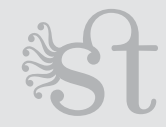

\title{
Gottfried Wilhelm Leibniz
}

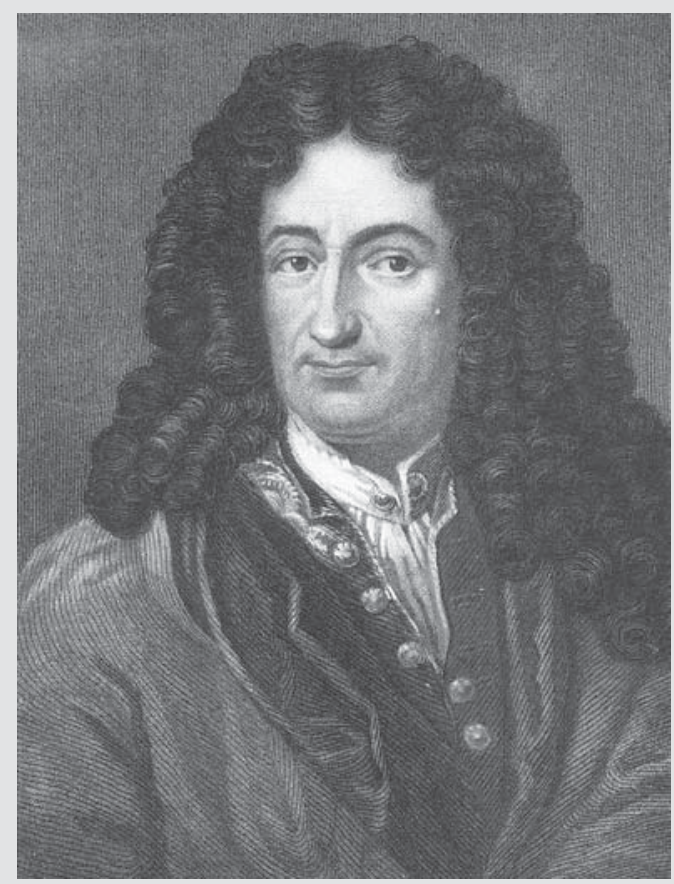

\section{Projeto a respeito de uma nova Enciclopédia que deve ser redigida pelo método da descoberta ${ }^{1}$}

Tenho pensado comigo muitas vezes que os homens poderiam ser muito mais felizes do que são, se aquilo que eles potencialmente têm, também o pudessem ter efetivamente, para que, assim que precisassem, pudessem usá-lo. Ora, a verdade é que nós mesmos não conhecemos nossas potencialidades; somos como um negociante que não faz o livro-caixa ou como uma biblioteca sem fichário. E também, do modo como agimos, talvez possamos ser úteis a nossos longínquos descendentes, nós próprios não colheremos os frutos de nossos trabalhos; vamos discutindo, vamos acumulando sem parar e raramente acabamos demonstrando algo ou fazemos disso um inventário; mal tiramos 
proveito de nossos estudos. E se assim continuarmos, deveremos cuidar para não ser atingidos por um mal incurável <e para que a ignorância não seja restaurada pela aversão ao estudo>, quando a exagerada quantidade de coisas e livros suprimir qualquer esperança de discernimento e o que é estável e útil for obscurecido pela massa de coisas sem valor.

Muitas vezes pensei sobre qual poderia ser a razão de tantos males, e até consultei homens ilustres, de cujas conferências ou escritos me foi permitido desfrutar; e como, enfim, me parecesse ter encontrado um remédio que, além de muito útil e eficaz, poderia estar em poder de alguns particulares e ser adquirido com poucos recursos; como, além disso, certos segredos da arte de descobrir me ocorressem como uma dádiva divina, ${ }^{2}$ comprovados pelo experimento de exemplos completamente claros e que, quando eu expuser em público, julgar-se-á que talvez eu tenha dado garantias não insignificantes de uma esperança maior; por tudo isso, ousei convidar alguns homens destacados por sua doutrina e sua reputação na república ${ }^{3}$ para um trabalho de conjunto.

Quero, porém, que tudo seja avaliado pelo parecer deles próprios não menos do que pelo meu; também não assumo outro papel do que o de alguém que incentiva; quanto ao resto, estarei em igualdade de condições, oferecendo-lhes a mesma colaboração que deles próprios desejo. Por isso, para avançar gradualmente, julgo dever primeiro comunicar os projetos, para que sejam estabelecidas quanto antes as regras do grupo que surgirão do assunto, e para que sua execução seja acelerada. ${ }^{4}$

Apresentarei aqui, entretanto, o resumo de meu projeto ou desejo, submetendo-o a críticos inteligentes. A respeito do modo, contudo, falarei um pouco mais distintamente e conversarei com aqueles que hão de aprovar a razão do plano e oferecerão auxílios mútuos.

O resumo do projeto consiste em uma ordenação adequada para encontrar os conhecimentos humanos mais importantes, reconhecidos há algum tempo como úteis para a vida. De fato, da mesma forma que, tendo sido construída uma certa tabela nas progressões dos números, costuma aparecer um modo de continuar essa tabela sem nenhum esforço, (como se alguém buscasse os números quadrados ou que resultam da multiplicação dos números por si mesmos, e o mostrasse na tabela, logo seria visível um modo muito fácil de completá-la só pela adição e sem nenhuma multiplicação).

$\begin{array}{lccccccccccc}\text { Números } & \circ & 1 & 2 & 3 & 4 & 5 & 6 & 7 & & & \\ \text { Quadrados } & \circ & 1 & 4 & 9 & 16 & 25 & 36 & 49 & 64 & 81 & 100 \\ \begin{array}{l}\text { Diferenças } \\ \text { ou ímpares }\end{array} & & 1 & 3 & 5 & 7 & 9 & 11 & 13 & 15 & 17 & 19\end{array}$


Projeto a respeito de uma nova Enciglopédia...

Pois se somares o número ímpar <15> a um número tal como 49 correspondente à fila dos quadrados, terás < o número> quadrado seguinte, 64, bastando apenas fazer a adição, sem a necessidade de multiplicar o número 8 por si, o mesmo ocorrendo com os números mais elevados <em que a multiplicação é mais difícil e por isso tem grande utilidade essa abreviação pelo uso da adição>. Dessa mesma forma, tendo sido retamente arranjadas as descobertas em qualquer gênero de coisas tal como feito na tabela, ficará muito mais fácil o modo de continuar as descobertas <isto é, de encontrar novas coisas>, do que se alguém tentasse encontrá-las isoladamente e como que separadas de sua série.

Como, porém, as coisas são maximamente visíveis e aparecem tal como numa tabela quando são propostas de modo simples e direto <despidas de toda dificuldade supérflua>, esta Enciclopédia deverá ser redigida segundo o modo matemático, por meio de proposições cuidadosa e rigorosamente concebidas, às quais, contudo, a título de ilustração, será lícito <freqüentemente> acrescentar escólios, nos quais será maior a liberdade de expandir-se. Pois é certo que não apenas a matemática, mas também todas as outras áreas do saber, podem ser tratadas < de modo distinto $>$ por certos enunciados ou teses. 5

[Essas questões devem ser dispostas segundo a ordem de descoberta...]

Até onde for possível, devem ser buscadas proposições <geralmente verdadeiras, nas quais devem ser distinguidos os graus; mas, se for possível fazer, utilizar principalmente> universais e entre essas preferir as que são recíprocas em relação ao sujeito, pois o uso delas é muito freqüente <também> na análise, já que aquelas não-recíprocas têm lugar quase somente na síntese. ${ }^{6} \mathrm{E}$ a isto se referem aquelas leis do filosofar que Aristóteles propôs ${ }^{7}$ e que os ramistas, ${ }^{8}$ em outra época, inculcavam.

Em qualquer ciência as proposições são ou princípios ou conclusões. Os princípios, por sua vez, são definições, axiomas, hipóteses <ou fenômenos>; desses (princípios) as definições em si certamente são arbitrárias, contudo devem acomodar-se ao uso comum e ser aprovadas pelo consenso dos colegas < a fim de que, entendidas de forma diversa por alguns, não gerem confusão em todo o corpo >.9

Os axiomas são as (proposições) que todos têm por evidente <e atentamente consideradas compõem-se de termos>.

As hipóteses são proposições de vasto uso e aceitação, e estão fundamentadas na conformidade das conclusões conhecidas em outra parte e delas dependentes; contudo, ainda não podem ser demonstradas de modo suficientemente preciso por nós, razão por que são assumidas provisoriamente.

Osfenômenos são proposições que são provadas pela experiência. Mas se a experiência não for fácil de fazer ou não for feita por nós mesmos, deve ser provada por testemunhos. ${ }^{10}$ Além disso, deve-se evitar experiências dúbias, a não ser que sejam de grande importância, <e nesse caso deve-se observar seu grau de confiabilidade>. 
As conclusões são observações, teoremas ou problemas. As observações acontecem pela simples indução a partir dos fenômenos. Os teoremas, porém, são descobertos pelo raciocínio a partir de alguns princípios, mas expressam unicamente o que é verdadeiro. Já os problemas referem-se à prática; daí por que se deve reconhecer que todas as demais coisas devem ser dirigidas aos problemas ou as ações úteis à vida.

Aordem das questões deve ser matemática, no entanto, diversa da de Euclides. ${ }^{11}$ Pois os estudiosos da geometria, é verdade, demonstram com precisão suas afirmações; porém, mais do que esclarecer o espírito, eles o coagem, fato que até gera maior admiração para eles, enquanto, malgrado o leitor, arrancam-lhe seu assentimento e envolvem-no com uma arte improvisada, mas não dão a devida atenção à sua memória e talento, porque de alguma forma ocultam as razões e causas naturais das conclusões, a fim de que se torne difícil reconhecer o modo pelo qual conseguiram suas descobertas. Mas, já que o mais importante em qualquer ciência é conhecer não apenas as conclusões e suas demonstrações, mas também as causas das descobertas, as quais basta reter na memória, porquanto a partir delas as outras coisas podem ser deduzidas com talento próprio, <por essa razão a luz da descoberta e o rigor da demonstração devem ser unidos, e> os elementos de qualquer ciência devem ser escritos de tal modo que um leitor ou estudante sempre veja a conexão entre eles e que, como um companheiro de descoberta de seu mestre, pareça mais acompanhá-lo do que segui-lo; é verdade que, desse modo, as ciências parecerão menos admiráveis, mas serão mais úteis e poderão mais facilmente ser divulgadas. <Mas para transmitir e escrever desse modo as ciências, é necessário encontrar homens capazes de descobrir <e que possuam verdadeiras razões>, pois devem descrevê-las, de tal modo como se eles mesmos as tivessem descoberto, o que evidentemente não é coisa para qualquer um. Segue-se disso> também que não <será> necessário antepor separadamente as definições e os axiomas, assim como os fenômenos ou as experiências. Porém, sejam essas coisas assumidas conforme ocorrer seu uso na ordem natural da reflexão.

Dispostas as proposições na sua ordem de descoberta, que se acrescentem índices ou catálogos nos quais as descobertas já entendidas serão colocadas em ordem para um uso fácil e para formar combinações como nas tabelas. Daí surgirão muitas coisas novas das quais de outro modo nem cogitaríamos e aparecerão certas séries harmônicas cujo caráter será manifesto percorrendo os termos maiores da série. ${ }^{12}$ Essa luz é também desejável nas ciências matemáticas e, assim como as outras ciências, a exemplo daquelas, devem procurar alcançar a certeza, assim também, em contrapartida, a rudeza das matemáticas deve ser abrandada, <a exemplo das outras (ciências),> por um certo modo mais agradável de tratar, de maneira que, ao mesmo tempo, obtenhamos a confiança da vontade e satisfaçamos claramente um ânimo desejoso de conhecer as causas. 
Na medida em que seja possível e onde o for, devem ser usadas figuras ou esquemas; no entanto, é necessário observar aqui uma coisa: que isto é mais importante para desenvolver as ciências do que para convencer alguém facilmente. Naturalmente, tanto as proposições quanto as demonstrações de proposições devem ser concebidas de tal modo que todas possam ser lidas e entendidas mesmo sem esquemas. Há de acrescentar-se, porém entre parênteses, a constante referência a letras esquemáticas. Posteriormente, para ajudar a imaginação, mas antes de tudo para ajudar o espírito, para obter conceitos distintos e para afastar o espírito das imagens, é necessário que aprendamos também a arte de descobrir, sem esquemas, apenas com a força da alma, e que fique evidente que a [força] <eficácia> da demonstração não dependa do traçado das figuras desenhadas. ${ }^{\mathbf{1 3}}$ Pela mesma razão também as demonstrações devem ser realizadas sem auxílio do cálculo algébrico, mesmo que esse seja muito usado, que tenha sido desenvolvido maximamente por mim e que seja necessário naquelas demonstrações que não podemos obter de outro modo; contudo, deve ser evitado sempre que as verdades puderem ser demonstradas pela razão natural que dirige o espírito por meio das próprias idéias das coisas. Por isso, ao tratar de estabelecer os elementos de qualquer ciência, é preciso evitar o uso do cálculo algébrico. Mas, quando temos bastante domínio em alguma ciência, o cálculo é, depois, particularmente útil, <para daí tirar conseqüências, além de vários casos e aplicações>, e para expor alguns resultados com um mínimo esforço do espírito. Nossa enciclopédia, portanto, há de ser escrita de modo que os enunciados e demonstrações de verdades não dependam nem de esquematismos nem do cálculo, mas das definições dos axiomas e das primeiras premissas. Deve-se, no entanto, acrescentar esquemas onde e quando for possível, mas o cálculo algébrico, ${ }^{\mathbf{1 4}}$ somente quando tem especial utilidade e elegância. Na verdade, para enunciar e demonstrar sem figuras as proposições, muitas vezes será preciso formar novas palavras (onomatopoieîn) para evitar as circunlocuções. Nisso, contudo, deve sempre ser visada a clareza e a concisão, ${ }^{\mathbf{1 5}}$ a fim de que nunca inventemos alguns nomes novos sem grande necessidade e uso, e se em alguma parte devem ser inventados, adotemos aqueles que, na medida do possível, concordem com o uso comum das palavras, para que não aconteça de tornarmos-nos obscuros ao procurar a economia de palavras. ${ }^{16}$

Serão incluídas nesta enciclopédia todas aquelas ciências que se baseiam ou exclusivamente na razão ou na razão juntamente com a experiência, naturalmente aquelas que não dependem da escolha de alguém que tenha alguma autoridade. Assim são separadas as leis divinas e humanas, <porque dizem respeito à vontade; excluem-se também> certas artes frívolas, ${ }^{\mathbf{1 7}}$ as quais não podem ser reduzidas a fundamentos firmes. Segundo o método citado, devem ser arroladas, portanto, principalmente as seguintes ciências: 
A primeira é a gramática ou a arte de entender aquilo que por nós for declarado no corpo desta enciclopédia. Por isso, deve ser posta à disposição primeiro uma gramática [universal] <racional>, adaptada em toda parte à língua latina e depois ilustrada pelo exemplo de outras línguas: que nela seja ensinado o significado regular de todas as partículas, flexões e posições das palavras. Assim, o significante pode sempre ser posto em lugar do significado, pois, para usar um exemplo, os casos dos nomes sempre podem ser eliminados, colocando em seu lugar algumas partículas com o caso nominativo, como se pode ver nas línguas [como a francesa] nas quais não há flexões de nomes, a não ser por meio de partículas. Os verbos sempre podem ser reduzidos a nomes, bastando acrescentar-lhes a forma verbal est (é). ${ }^{18}$ Os advérbios estão para os verbos como os adjetivos estão para os substantivos. Por fim, devem ser substituídas as significações das partículas até chegar-se àquelas que não podem ser eliminadas por nenhuma explicação; tais são est (é, está), et (e), non (não) e deve-se estabelecer delas o número preciso; e somente a partir delas, juntamente com o caso nominativo dos nomes, todas as demais (partículas) podem ser explicadas. Isso deve aparecer na própria obra. E esta é a verdadeira análise dos caracteres que o gênero humano comumente usa na fala e mesmo no ato de pensar. Deve-se, porém, considerar atentamente a regularidade da gramática sem muita preocupação com as anomalias, porque ela deve ser escrita não tanto para que seja aprendida só como língua, quanto para que seja feita a análise minuciosa das palavras. Pois, na lógica, muito freqüentemente ocorrem inferências que não devem ser demonstradas a partir de princípios lógicos, mas a partir de princípios gramaticais, isto é, a partir do significado das flexões e das partículas. Tal gramática, contudo, pode ser ajustada nessa mesma obra de forma que também possa ser maravilhosamente útil aos que a estudam.

Segue-se a Lógica, pela qual entendo, apenas aqui, a arte das conclusões ou arte de julgar o que é proposto, que deve ser estabelecida a partir da prática dos homens quando falam e escrevem. Por certo, os modos das inferências que ocorrem nas falas em toda parte devem ser divididos em classes e derivados de certas classes simples, mostrando de que modo essas conexões, ainda que não reduzidas a outra forma, à maneira das escolas, ${ }^{19}$ mas deixadas naquela que apresentam no uso comum e nos autores, ainda assim, tenham força ou concluam pela forma, e possam ser demonstradas na forma comum das escolas. Porém, a lógica será usada para que as formas de raciocinar mais compostas, desordenadas e implícitas, que, entretanto, aparecem freqüentemente na vida, sejam reduzidas a regras com base nas quais possam ser classificadas por meio de um compêndio, para que não seja sempre necessária sua redução às figuras e aos modos das escolas. Merece, de fato, ser divulgado de que modo os matemáticos competentes encontraram seus vários padrões ou formas de cálculo, os quais concluem com exatidão, ainda que nem sempre coloquem em ordem os caracteres segundo 
o modo usual dos principiantes. Isso merece ser divulgado, para que saibamos que podemos servir-nos deles com segurança; assim, os homens competentes na arte de falar e pensar adquiriram para si diversos padrões de raciocínio e expressão, os quais geram conclusões não menos pelo poder da forma do que pelos modos dos escolásticos; mas necessitam ser demonstrados a partir dos modos das escolas, usando uma gramática racional que explique aquelas partículas, e devem ser unidos por meio de certas leis que, se observadas, mostram que seu uso é seguro. ${ }^{20}$

A terceira é a arte mnemônica, quer dizer, a arte de reter e recordar aquilo que aprendemos, arte que utiliza muitos resumos bem elaborados e muitas descobertas, cujo uso nos pode ser útil algumas vezes na vida. Em primeiro lugar, porém, parte dela deve ser cultivada, a saber, a arte da recordação, com cuja ajuda lembramos aquilo de que temos necessidade e que está de forma latente em nossa memória, mas que não vem à tona; uma coisa é reter, outra é recordar, pois nem sempre conseguimos recordar aquelas coisas que retemos, a não ser que por alguma razão sejamos estimulados.

A quarta ciência é constituída pelos tópicos ou arte de descobrir, vale dizer, direcionar os pensamentos para desvendar alguma verdade desconhecida, ou descobrir os meios para um certo fim. A essa área pertencem os lugares comuns dialéticos, aquela parte da retórica que se chama inventio, ${ }^{21}$ a arte das sutilezas, a criptografia ${ }^{22}$ e, finalmente, a álgebra; nelas se apresentam belos exemplos da arte dos tópicos que devem ser conhecidos por aqueles que pretendem ensinar esta arte, para que não confundam a álgebra com uma prática geral, ${ }^{23}$ mas para que, a partir disso, formem regras mais universais que possam, contudo, ser ilustradas nas escolas por meio de exemplos especiais.

A quinta é a arte das formas, ${ }^{24}$ que trata do mesmo e do diverso, do semelhante e do diferente, isto é, das formas das coisas, mas afastando o espírito da consideração da magnitude, da posição, [da ordem] e da ação. A este campo pertencem as fórmulas e comparações das fórmulas, e desta arte dependem muitas regras que os algebristas e geômetras passaram a usar, ainda que elas não se refiram apenas às magnitudes, mas também a outras considerações. ${ }^{25}$

A sexta ciência é a logística, que trata do todo e das partes, quer dizer, da magnitude em geral, das razões e das proporções, e que inclui o livro quinto dos Elementos de Euclides, ${ }^{\mathbf{2} 6}$ como também grande parte da álgebra.

A sétima é a aritmética, que versa sobre a expressão distinta das magnitudes através dos números.

A oitava é a geometria ou a ciência da posição e das figuras. Ela será utilmente separada nas seguintes partes: elementar plana, elementar sólida, cônicas, orgânica, transformações. ${ }^{27}$ Convém saber que também a geometria <elementar> ainda não foi apresentada como seria de desejar. <Aqui ainda deve ser citada a geodesia, como também parte da engenharia civil e militar, a arte do torneiro e a do tecelão, todas elas enquanto 
não consideram a matéria. Aóptica também é puramente geométrica, sendo poucos os fenômenos tomados somente da natureza. ${ }^{28}$

Anona ciência trata da ação e da reação, a saber, a mecânica ou o estudo da força e do movimento. Esta ciência conecta a física com a matemática. Aqui também não se trata do modo como devem ser descritas as trajetórias dos movimentos, se elas são consideradas contínuas, pois isto é algo próprio da geometria, ${ }^{29}$ mas do modo como as direções e as velocidades dos movimentos são alteradas pelo choque dos corpos: o que não é possível conseguir somente pela imaginação e, por isso, é necessário uma ciência superior. Aqui se deve tratar da <estática>, da solidez das estruturas, da balística, de aspectos da pneumática e da hidrostática, da navegação a vela <bem como de outras partes da mecânica, para onde se deve remeter também a maioria da harmônica >

A décima ciência, a qual costumo chamar peografia,${ }^{3 \circ}$ trata das qualidades sensíveis. Tanto quanto possível deve-se definir essas qualidades, distingui-las pelas variedades e pelos graus, e enumerar as substâncias nas quais existem e pelas quais são produzidas e, enfim, aquilo que delas decorre. Tais qualidades, entretanto, ou são simples e, como tais, não podem ser descritas, mas para poderem ser conhecidas devem afetar nossos sentidos, sendo elas: a luz, a cor, o som, o odor, o sabor, o calor, o frio; ou são compostas <e podem ser explicadas por meio de uma descrição e, por isso, são de algum modo inteligíveis,> tal como a solidez, a fluidez, a flexibilidade, a tenacidade, a capacidade de fender, de quebrar e outras coisas desse gênero; da mesma forma, o volátil, o fixo, o solvente, o coagulante e o precipitante. Na verdade, aquelas qualidades simples supracitadas não podem ser objeto de raciocínios, a não ser enquanto costumam ser associadas com as compostas, <e também com a grandeza, a posição e o movimento, qualidades comuns citadas anteriormente $>$. Por isso, aquelas qualidades simples devem ser tratadas historicamente, ${ }^{3 \mathbf{1}}<$ isto é>, deve ser descrito de que modo elas costumam estar unidas entre si e de que modo costumam estar unidas com outras qualidades inteligíveis. As qualidades inteligíveis ou mistas caem sob a consideração da geometria e da mecânica e, assim, podem ser descobertos teoremas a respeito de suas causas e de seus efeitos, por onde também será possível fazer algum juízo sobre as causas e os efeitos das qualidades meramente sensíveis. Toda a física, portanto, tem por ponto capital a cuidadosa enumeração dessas qualidades e sua distinção por meio de graus, e de que modo costumam associar-se entre si na mesma substância ou em diversas, que têm, contudo, certa adequação ou alguma conexão e relação.

A décima primeira ciência, denominada homeografia, trata das substâncias pertencentes, ao menos, à mesma espécie, na qual se deve iniciar o estudo a partir daquelas coisas que de fato são muito semelhantes e maximamente comuns, como aqueles quatro corpos que o vulgo chama elementos; a partir daí há de avançar-se em direção daquelas coisas que são menos comuns, porém mais dotadas de qualidades variadas, 
tal como os sais, as seivas, as pedras, os metais. Tais qualidades desses corpos devem ser enumeradas de acordo com seus graus e suas diferenças, tanto aquelas que se mostram espontaneamente aos sentidos em um corpo bruto, como aquelas que nele surgem pela sua manipulação ou pela mistura com outros corpos. Note-se que convém iniciar por aquelas qualidades espontâneas, que os corpos também devem ser manipulados em si de vários modos, isto é, não apenas com aqueles corpos muito comuns, como ar, terra, água e fogo, como também com outros pelos quais são afetados minimamente, ou por aqueles que confundem o menos possível a busca das causas. Então, usando a melhor forma de busca das qualidades, poderá ser determinada a natureza da substância, enquanto isso for possível a partir dos dados observados; não tenho dúvidas de que, dentro de poucos anos, por meio desta arte, poderemos obter ótimas informações sobre a estrutura interior dos corpos.

A A duodécima é a cosmografia, ou ciência dos maiores corpos do universo. Aqui deve ser apresentada a astronomia física, que não explique os fenômenos apenas por hipóteses, mas também tente mostrar qual hipótese é a mais verdadeira ou é certamente mais provável. ${ }^{32}$ A esta área do saber pertence o conhecimento dos fluidos gerais, visíveis e invisíveis, que nos cercam e nos invadem, nos quais esses grandes corpos flutuam, ${ }^{33}$ e deve-se pesquisar se as espécies e os movimentos desses fluídos podem ser definidos por alguma razão a partir dos fenômenos produzidos pelos corpos do universo. Aqui também cabem considerações a respeito das grandes mutações de nosso globo e de suas causas, como também a meteorologia. $\mathbf{3}_{4}$

A décima terceira ciência é a dos corpos orgânicos que alguns costumam chamar espécies. Essa ciência poderia ser chamada idografia. As espécies, no entanto, devem ser distinguidas cuidadosamente, não segundo forma comum por meio de dicotomias, ${ }^{3} 5$ mas pelas combinações das qualidades a partir das quais podem ser discernidas. Mas deve-se considerar atentamente a causa daquelas propriedades que aparecem diretamente aos sentidos; as demais <contudo, contanto que sejam experimentadas>, devem ser registradas com não menos atenção, designadas pelas diferenças e graus, ser nomeadas e ser mostradas por meio de índices. Por outro lado, do mesmo modo que nas substâncias similares, também nas orgânicas deve-se avançar gradualmente, <no caso de pesquisar suas qualidades $>$. Em primeiro lugar, devem ser consideradas aquelas qualidades que as espécies de mesma natureza têm, aquelas que se mostram apenas aos sentidos (a começar pelo sentido da visão), depois aquelas que as espécies adquirem ao serem manipuladas ou deixadas a si mesmas (isto é, a si mesmas e à ação do ar), $<$ ou quando unidas a outros indivíduos semelhantes a elas (pois nisto diferem das substâncias similares) ou quando examinadas em conjunto com água e fogo> e com outros corpos com os quais, antes de tudo, muito se assemelham; e, finalmente, quando estão unidas com os corpos mais compostos e até com aquelas mesmas espécies e com os 
corpos de animais, porque toda essa pesquisa deve ser orientada para o conhecimento da natureza dos animais.

A décima quarta é a ciência moral, quer dizer, aquela que trata acerca do espírito e do conhecimento e orientação de suas tendências. [Aqui incluo a política e a jurisprudência]. ${ }^{36}$

A décima sexta é denominada [cosmopolítica], geopolítica, vale dizer, [o estado do gênero humano] trata do estado de nossa Terra relacionado ao gênero humano, que inclui o estudo de toda a história e da geografia civil. ${ }^{3} 7$

Adécima oitava ciência tem por objeto o estudo das substâncias incorpóreas, quer dizer, a teologia natural.

A prática deve ser subordinada a esta enciclopédia, isto é, o uso das ciências para a conquista da felicidade, ou para aquilo que devemos fazer, considerando-se, naturalmente, que somos apenas seres humanos. E já que é de máxima importância que estas ciências sejam ensinadas com suficiente perfeição, é preciso também que, antes de tudo, usemos bem nosso tempo; em razão disso, é meu desejo que quanto antes elaboremos, com trabalho conjunto entre muitos, do modo mais acabado possível, algum esboço dela. Que essa enciclopédia seja a base dos demais saberes, que seja possível ampliá-la e também aperfeiçoá-la ao longo do tempo, e possa tornar-se degrau para alcançar algo maior. Não vejo dificuldade para que isso possa ser executado por vinte homens cultos dentro de dois anos, para o que, por certo, seriam necessários dez anos, se feito por um só que tenha suficiente conhecimento das coisas.

[Mas admite-se que qualquer indivíduo [entre os curiosos] < daqueles que desejam a verdade e consideram as coisas de modo mais profundo $>$ costuma ter muitos pensamentos e descobertas].

E como é sabido, porém, que certos homens, que se sobressaem por sua fecunda doutrina e pelo especial desejo de verdade, costumam ter muitos pensamentos brilhantes <ou experiências>, ainda que dispersos e variados, que não confluem para formar o corpo de uma única ciência e que costumam perder-se, causando grande perda à república, tais pensamentos e experiências, se forem expressos no papel e comunicados, mesmo que não bem elaborados <e de modo incoerente>, ajudarão admiravelmente todo este plano e, ao mesmo tempo, contribuirão para sua glória, e tal sociedade proporcionará a cada um, com a máxima fidelidade, uma justa reputação pelas suas descobertas. 
Notas ao Projeto a respeito de uma nova Enciclopédia...

\section{Notas}

1 A tradução deste texto foi feita a partir do texto latino que se encontra na edição de Couturat, Opuscules et fragments inédits de Leibniz, p. 3o-411, 1988. Em nossa tradução, usamos os mesmos signos que se encontram na edição de Couturat:

| marca a separação de duas páginas consecutivas do manuscrito;

[....] encerram frases ou palavras que Leibniz suprimiu;

$<\ldots$. . encerram frases ou palavras que Leibniz acrescentou;

$\{\ldots$. ... encerram notas ou adições marginais.

2 Possível referência à descoberta do cálculo infinitesimal.

3 Alusão à República das Letras, nome dado no século xvıı ao conjunto de intelectuais e cientistas europeus. Eles tinham formado uma rede cujos membros mantinham contato por correspondência. O padre Mersenne foi uma figura destacada dessa rede.

4 Aqui aparece em Leibniz a idéia de que o conhecimento científico é uma tarefa coletiva, um trabalho que se realiza em grupo. No século xvı foram fundadas várias sociedades científicas, dentro das quais eram discutidos experimentos e teorias científicas. As mais conhecidas foram a Royal Society na Inglaterra, a Academie Royale des Sciences na França, a Accademia dei Lincei e a Accademia del Cimento na Itália.

5 Vemos aqui a idéia leibniziana de estabelecer uma ordem matemática entre nossos conhecimentos. Diferentemente de nossas enciclopédias que organizam o conhecimento segundo a ordem alfabética, Leibniz pensava que na sua enciclopédia os conhecimentos deviam ser organizados como resultado da análise, do método matemático de descoberta cuja origem está na geometria grega.

6 Em nossa introdução dissemos que não iríamos entrar na discussão sobre a interpretação do método da análise e síntese na geometria grega. Aqui é suficiente dizer que os filósofos da Idade Moderna caracterizaram a análise como um método de descoberta de verdades. Esse método foi contraposto, por eles, à silogística aristotélica, como o fértil ao estéril. Em Arnauld \& Nicole (1970, p. 374), encontramos uma caracterização da análise e da síntese. O método de análise e síntese exige que ao chegar à conclusão obtida por análise, seja possível fazer o caminho inverso da conclusão às premissas através da síntese. Se as conclusões obtidas pela análise são recíprocas a suas premissas, a possibilidade de fazer o caminho inverso está garantida. Mas isso nem sempre acontece. Sobre a questão da direção da análise cf. Hintikka \& Remes, 1983; Gulley, 1983; Robinson, 1983. As proposições que são recíprocas em relação ao sujeito são aquelas cujo predicado pode ser colocado no lugar do sujeito salva veritate. Por exemplo, todo homem é um bípede sem penas. Esse enunciado é um enunciado de identidade do tipo homem = bipede sem penas. Leibniz pensava que num arrazoado formado por uma cadeia de enunciados de identidade, as premissas são recíprocas à conclusão. 7 Referência às leis de conversão da lógica aristotélica, nas quais o sujeito e o predicado trocam de lugar. Assim de Nenhum homem é peixe inferimos Nenhum peixe é homem e recíprocamente.

8 Petrus Ramus ou Pierre de la Ramée foi um lógico e filósofo francês do século xvi, cujos discípulos foram chamados de ramistas.

9 Corpo significa aqui o corpo da ciência.

10 No século XVII, houve grande discussão sobre o valor que devia ser dado aos testemunhos. Na Lógica de Port Royal lemos que há duas vias que nos levam a acreditar que uma coisa é verdadeira: ou pela razão ou pela fé. Santo Agostinho já tinha afirmado que: "Quod scimus, debemus rationi; quod credimus, auctoritati" ("O que sabemos, devemos à razão; o que cremnos, à autoridade") (apud Arnauld \& Nicole, 1970, p. 409). A fé pode ser divina ou humana, sendo esta última o testemunho dos homens. "[...] ily a des choses que nous ne connoissons que par une foi humaine, que nous devons tenir pour aussi certaines \& aussi indubitables, que si nous en avions des démonstrations mathématiques: comme ce que l'on sait par une relation constante de tant de personnes, qu' il est impossible qu' elles eussent pu conspirer ensemble pour assurer la même chose, si elle n’ etoit vraie” (“[...] há coisas que conhecemos apenas por uma fé humana, que devemos tomar por tão certas e tão indubitáveis, como se tivéssemos delas demonstrações matemáticas; como aquilo que sabemos por uma relação constante de tantas pessoas, que é impossível que pudessem ter conspirado em conjunto para assegurar a mesma coisa, se ela não fosse verdadeira") (Arnauld 
\& Nicole, 1970, p. 410). Devido ao seu interesse pelo tipo de provas usadas no direito, Leibniz se ocupou do valor probatório dos testemunhos.

11 Leibniz preferiu a ordem analítica gerada pelo método de análise à ordem sintética dos Elementos de Euclides. A análise nos mostra as causas de nossas descobertas, o modo pelo qual as conseguimos. Além disso, a análise coincide com a ordem natural da reflexão, ao passo que a síntese segue a ordem lógica, partindo dos axiomas e das definições. 12 Como matemático, Leibniz deu grande importância ao estudo das séries numéricas. Uma de suas descobertas foi encontrar a expressão em série de $\pi / 4=1-1 / 3+1 / 5-1 / 7 \ldots$ Por meio dessa série podemos ter uma expressão de $\pi / 4$ através de uma lei. Leibniz fez várias tentativas de traduzir em termos numéricos a inferência lógica, associando números aos conceitos sujeito e predicado que aparecem nas premissas e na conclusão. Com base nesses procedimentos, Leibniz provou a correção das inferências que ocorrem no quadrado aristotélico da oposição. Ver, por exemplo, os trabalhos Modus examinandi consequentias per números (Modo de examinar as conseqüências por meio de números) e Regulae de bonitate consequentiarum (Regras para extrair boas consequiências) (Leibniz, 1988, p. 71-92).

13 Leibniz, como Descartes, pensava que o principal defeito do método de análise da Geometria grega é que ele depende em grande parte da consideração de figuras, isto é, da capacidade de imaginar ou desenhar a construção geométrica apropriada para a resolução de um problema dado. Leibniz tentou aperfeiçoar a análise dos gregos, substituindo as figuras por caracteres. Dessa forma, pensou ter intelectualizado o método de análise.

14. Aqui com a expressão cálculo algébrico Leibniz faz referência à Geometria algébrica de Descartes. O defeito que Leibniz encontrava na exposição cartesiana da geometria por meio da álgebra é que ela pressupunha sem demonstrar a validade dos axiomas e postulados de Euclides e das proposições que decorrem deles. Assim, por exemplo, ao representar uma circunferência por meio da equação $x^{2}+y^{2}=r^{2}$ estamos pressupondo a verdade do teorema de Pitágoras, que é demonstrado a partir dos axiomas e postulados de Euclides.

15 Couturat introduz a seguinte nota de rodapé ao texto de Leibniz (cf. 1988, p. 35): "Isso lembra o lema de Leibniz: In signis claritatem, in rebus usum (nos signos clareza, nas coisas utilidade)".

16 Couturat também introduz a seguinte nota de rodapé ao texto de Leibniz (cf, 1988, p. 35): "Lembrança de Horácio (Epistulae, II, 25-6): Brevis esse laboro, Obscurus fio (Na medida em que busco ser conciso, posso tornar-me obscuro)". 17 Possível alusão às artes mágicas como a astrologia, a numerologia e a alquimia. No século xviı, houve grande interesse por essas artes (cf. Rossi, 1990, Cap. 1).

18 Leibniz privilegia a forma de enunciado $S e ́ P$ (Sujeito, verbo cópula).

19 Na lógica aristotélica, ou lógica das escolas, a validade das formas de inferência decorre de sua redução às formas válidas da primeira figura.

20 Leibniz reconheceu que os matemáticos e jurisconsultos tinham encontrado certas formas de raciocinar que não podiam ser reduzidas àquelas formas válidas caracterizadas dentro da lógica aristotélica. Como parte de seu programa logicista de redução da matemática à lógica, ele entreviu a possibilidade de estender a lógica aristotélica no intuito de demonstrar a validade das formas de inferência usadas na matemática e no direito. Ver, por exemplo, a carta de Leibniz a Gabriel Wagner (GP, vol. II, p. 515-27).

21 A retórica antiga tinha três partes: a inventio, $u$ arte de descobrir argumentos para apoiar uma tese, a dispositio, ou arte de relacionar esses argumentos de forma que seja originado um discurso coeso, e a elocutio, ou arte de apresentar esses argumentos, sejam eles escritos ou falados, para obter a máxima persuasão. Retórica e dialética compartilham juntamente com a lógica a característica de serem disciplinas formais, pois não versam sobre conteúdos específicos, mas sobre a forma do discurso (cf. Reboul, 1988, Cap. 3).

22 Traduzimos por criptografia, a expressão leibniziana ars deciphratoria sive divinatoria .

23 Leibniz polemizou contra os cartesianos que consideravam a álgebra como um método universal de descoberta. Sem negar o valor da álgebra, Leibniz pensou que ela sozinha não podia constituir um método desse tipo. Para obter um método universal de descoberta, pensava Leibniz, era preciso ir além da álgebra, criando uma Característica Universal ou linguagem artificial universal.

24. As qualidades eram chamadas de formas pelos escolásticos.

25 A matemática de Leibniz ultrapassava o âmbito do quantitativo, isto é, das grandezas para considerar relações qualitativas como a semelhança. Leibniz desenvolveu duas disciplinas matemáticas, a combinatória e a analysis situs para tratar desses aspetos qualitativos. 
Notas ao Projeto a respeito de uma nova Enciclopédia...

260 livro V dos Elementos contém a teoria das proporções desenvolvida por Eudoxo. Essa teoria permitiu resolver a crise originada dentro da Matemática grega pela descoberta das magnitudes incomensuráveis. O que Eudoxo fez foi dar sentido matemático também às expressões do tipo $a / b=c / d$ no caso em que $a$ e $b$ sejam magnitudes incomensuráveis entre si. Historiadores da matemática consideram que a crise dos irracionais e a sua resolução por meio da teoria das proporções desenvolvida por Eudoxo originaram uma geometrização da matemática grega que abandonou, dessa forma, o paradigma aritmetizante dos pitagóricos (cf. Boyer, 1974, Cap. 6; Szabó, 1977).

27. No século Xvı a geometria plana trata das figuras no plano e a sólida das figuras no espaço tridimensional. Além disso, a geometria se ocupa das cônicas, isto é, das figuras geradas pela seção de um cone por um plano. Por outro lado, os geômetras se interessavam pelas transformações, cujo estudo consistia na determinação dos métodos para transformar a área de uma figura curvilínea na área de um quadrado.

28 A transformação da óptica em uma disciplina geométrica, que vinha acontecendo desde a Renascença, atinge no século xvir seu ápice através dos trabalhos de Snell, Descartes, Huyghens e Newton. Snell descobriu a lei exata de refração da luz. Descartes tentou explicar esse fenômeno partindo da suposição de ser a luz constituída de pequenas partículas em rápido movimento linear. Com base nessa concepção da luz, Descartes ofereceu uma explicação mecânica e geométrica do arco-íris.

29 Em sua Geometria, Descartes distinguia entre as curvas geométricas, objeto de estudo da geometria, e as curvas mecânicas que não são estudadas por essa ciência. As curvas mecânicas cartesianas se identificam com aquilo que hoje chamamos de curvas transcendentes, isto é, com aquelas linhas que não podem ser representadas por meio de um polinômio com coeficientes racionais, por exemplo, a curva exponencial $y=e^{x}$. Descartes considerava que as curvas geométricas eram aquelas geradas por dois movimentos cujas velocidades são comensuráveis entre si, ao passo que as mecânicas eram aquelas geradas por dois ou mais movimentos cujas velocidades são incomensuráveis entre si. (cf. Boyer, 1974, p. 250). Leibniz denominava foronomia a descrição puramente geométrica dos movimentos. 3o Termo provavelmente derivado do grego $\pi$ oto $\varsigma$ - $\alpha$-ov, adjetivo interrogativo que significa de que qualidade?

31 História significa para Leibniz o conhecimento do singular.

$3_{2} \mathrm{O}$ que Leibniz quer dizer é que se deve considerar a hipótese que não apenas salva os fenômenos, mas também é verdadeira. No século xviı, houve uma intensa discussão sobre como considerar os modelos astronômicos do sistema solar e do universo, se como hipóteses matemáticas aptas para a predição e o cálculo do movimento dos astros ou como descrições verdadeiras da realidade (cf. Losee, 1979, Cap. 6; Duhem, 1984).

33 No século xvir, era comum entre os astrônomos a crença de que os corpos celestes flutuavam no meio do éter.

34. A Meteorologia abrange, no século xviı, o estudo dos meteoros e dos fenômenos atmosféricos como os ventos e o arco-iris.

35 O método da dicotomia é o método das divisões de conceitos, cujo exemplo mais famoso encontramos no Sofista de Platão. Na Idade Moderna, esse método foi apresentado nas obras sobre lógica de Petrus Ramus (cf. Kneale \& Kneale, 1991, Cap. 5).

36 Leibniz omitiu a ciência correspondente ao número 15 .

37 Leibniz omitiu a ciência número 17 .

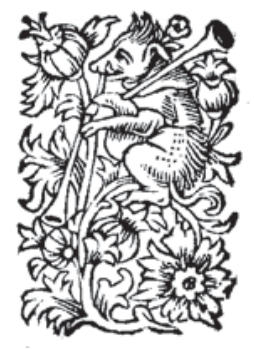

